\title{
Social integration of the older thalassaemic patient
}

\author{
C Politis, A Di Palma, M Fisfis, A Giasanti, S C Richardson, C Vullo, G Masera
}

\begin{abstract}
Because social policy favours the fullest possible social integration of chronically ill patients, we have evaluated the facilities that are needed to achieve this for patients with $\beta$ thalassaemia major in the light of the therapeutic advances that now permit them to survive into adulthood. We have investigated the social integration of adolescent and young adult thalassaemic patients, 171 from Greece and 112 from Ferrara in Italy. Patients in both areas show a good level of social integration and favourable self image, indicating what may be achieved by providing psychosocial support as part of a comprehensive approach to treatment.
\end{abstract}

$\beta$ Thalassaemia is a chronic, genetically determined haematological disorder characterised by severe haemolytic anaemia as a result of deficient synthesis of $\beta$ chains of the haemoglobin. ${ }^{12}$ The anaemia demands frequent blood transfusions to maintain life, while haemosiderosis and other complications of the disease require a continuous and distressing treatment regimen that includes parenteral iron chelation treatment, regular medical supervision, frequent admission to hospital, and (on many occasions) operation. Until a few years ago thalassaemia was regarded as a uniformly fatal disease and death was expected to occur before adulthood. Recent developments, however, have introduced brighter prospects of survival given good compliance with the latest treatments. ${ }^{3}$ Thalassaemia should no longer be seen exclusively as a disease of childhood, for patients now have the prospect of survival beyond adolescence in countries whose health services are able to supply adequate treatment.

To some extent the limiting factor in survival is the psychological element in compliance with the treatment protocol, which is related to coping with the many problems that we shall describe. The provision of psychosocial support for patients is therefore of primary importance and is an important topic of investigation. Continuity of support may be important too: in many places the structure of the health services requires that patients be transferred from paediatric to adult units at adolescence, a move which can have an adverse effect on the young patient who has formed a stable relationship with familiar medical staff.

As with every chronic disease, thalassaemia is liable to lead to difficult social and psychological problems. ${ }^{4}$ These arise particularly from the hereditary nature of the disease, the likelihood of physical deformity (especially of facial appearance), and the demands of regular blood transfusion and painful, time consuming iron chelation treatment. The difficulties can only increase if the older thalassaemic patients are unable to adopt the normal roles of adults in society. The ability to find adequate employment-or any at all-may be affected by the need for frequent time off for transfusion and other treatment, a factor that may already have had an impact on the level of education achieved. The probability of marriage and parenthood may in the past have been reduced by the disease's association with retarded sexual development. A further possible complication, affecting both the health and social condition of the patient, is diabetes.

It is clear that there are formidable obstacles to the integration of the thalassaemic patient into normal life, even though the need for this is well understood. ${ }^{4}$ Under these circumstances, it is important to gain an understanding of thalassaemic patients' present position in society and quality of life, to identify relevant social and psychological factors, and to establish what can be achieved by the provision of appropriate support facilities.

The operative word in this is 'support', as in many cases the old attitudes persist; the patient must be protected and normal expectations in respect of education, work, sexual development, and reproduction do not apply.

The present paper offers a comparative description of two preliminary studies of adolescent and adult thalassaemic patients, one conducted in Greece (C Politis, M Fisfis, C Richardson, et al. The social status of the thalassaemia patient in Greece. Presented at 2nd International Conference on thalassaemia and the haemoglobinopathies, Crete, 1987) and the other in Italy. Both the treatment units are long established specialist centres for the care of thalassaemic patients of all ages in areas where the disease is an important social problem, and both offer a degree of psychosocial support to their patients. The results show that it is possible to achieve social integration for most thalassaemic patients, they offer a basis for comparison with other areas where no or minimal support is available, and they point to contrasts between these two different areas of southern Europe.

Patients and methods

The studies were performed independently in the Red Cross Thalassaemia Unit in Athens, Greece, and the Microcytemia Centre in Ferrara, 
Italy. The Athens centre, established in 1955, cares for about 300 transfusion dependent thalassaemic patients drawn not only from the city but from all parts of southern Greece; the Ferrara unit, set up in 1972, treats about 170 patients from the immediate area of the city. Neither centre refers its patients elsewhere for treatment at adolescence. The centres follow similar policies of a multidisciplinary approach to the medical treatment and psychosocial support of their patients. Transfusion and other medical care is provided in two sessions a day in each centre. In Athens the therapeutic team comprises haematologists, paediatricians, specialised nurses, social workers, and psychologists, with a ratio of about one physician, two to three nurses, and one social worker to every 50 patients. The group in Ferrara comprises only paediatricians and nurses with a ratio of one physician to 42 patients, and one nurse to every 56 patients.

The sample sizes for the studies were 171 (88 male and 83 female patients) in Athens, and 112 ( 59 male and 53 female patients) in Ferrara; all patients were in the age range 14 to 34 years. The investigations were conducted by personal interview using questionnaires covering demographic data and items on topics relating to social integration including education, occupation, self image, and attitudes towards physical appearance. Both questionnaires consisted chiefly of precoded questions. Although the questionnaires were designed independently by the Greek and Italian medical groups (in collaboration with the Focus Social Research Centre, Athens, and the Sociology Department of the University of Messina, respectively), much basic information was covered by ques-

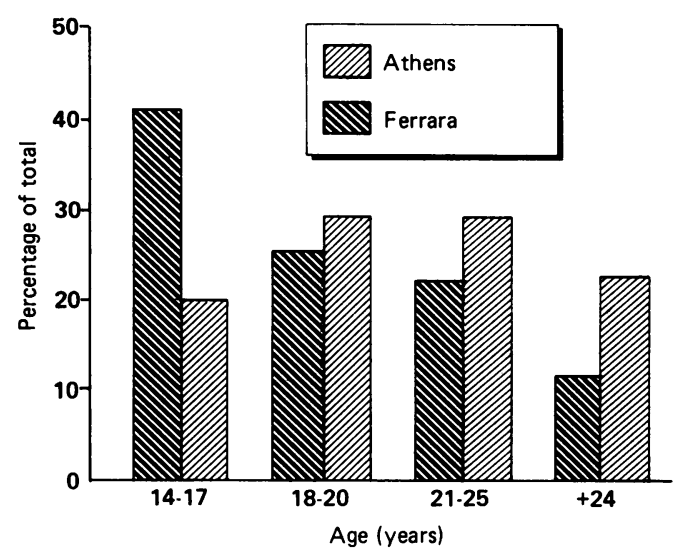

Age distribution of patients in Athens (male:female ratio 51:49) and Ferrara (male:female ratio 53:47). tions that were sufficiently similar to permit comparison between the two surveys. In addition to the information gathered by interview, the presence of diabetes was noted from the medical history.

\section{Results}

The age distribution of patients is shown in the figure. Patients in Ferrara tended to be younger than those in Athens. Of those aged over 25 years, three of five male and five of eight female patients in Ferrara were married, compared with none of 22 male and two of 16 female patients in Athens. There were also three younger married patients in the Athens Red Cross group whereas there was no married thalassaemic patient in Ferrara under 25 years of age.

Thirty eight (22\%) of the 171 Athens patients and four (4\%) of the 112 Ferrara patients had only elementary education $\left(\mathrm{p}<0.0001, \chi^{2}\right.$ test $)$, and 46 (34\%) of the 136 patients aged over 18 years in Athens had received or were receiving university level education, compared with only four of 65 $(6 \%)$ in Ferrara $(p<0.0001)$.

Data concerning occupation are presented in table 1. 'Housewives' in Athens were those who said that they were occupied with household duties, irrespective of marital state; in Ferrara, housewives were not recorded separately from the 'unemployed' category. A log linear model relating occupation (housewives were combined with 'unemployed' in Athens), sex, age, and place was found to require the inclusion of the interaction term between occupation and place $\left(\chi^{2}{ }_{2}=12 \cdot 43\right.$, $p=0.002)$; this means that the distribution of occupations was not the same in the two cities, even after controlling for sex and age differences. It is noticeable that in Athens there were more students and fewer unemployed than in Ferrara. The occupational distribution of the Greek patients did not differ from that of the Greek general population, whereas the Ferrara patients included both more students and more unemployed, and correspondingly fewer who were employed, than the Italian general population in the same age range (table 2).

Responses to an item concerning satisfaction with work were similar in the two cities; $30 \%$ of working patients in Athens and 31\% in Ferrara said that they were satisfied with their work. In addition, patients in Athens currently receiving higher education were asked how satisfied they were with their studies, and $22 \%$ responded that they were satisfied.

Satisfaction with available ways of spending one's free time was investigated in Ferrara by means of a five point scale of agreement or disagreement, to which $81 \%$ of patients responded

Table 1 Patients' occupations by sex, age, and city. Values are expressed as a percentage of each group

\begin{tabular}{|c|c|c|c|c|c|c|c|c|c|}
\hline \multirow{2}{*}{$\begin{array}{l}\text { Age (years) } \\
\text { and city }\end{array}$} & \multicolumn{4}{|c|}{ Male patients } & \multicolumn{5}{|c|}{ Female patients } \\
\hline & Total No & Studying & Employed & Unemployed & Total No & Studying & Employed & Housewife & Unemployed \\
\hline $\begin{array}{r}\text { Athens: } \\
14-17 \\
18-20 \\
21-24 \\
\geqslant 25\end{array}$ & $\begin{array}{l}20 \\
20 \\
26 \\
21\end{array}$ & $\begin{array}{l}80 \\
45 \\
31 \\
10\end{array}$ & $\begin{array}{r}5 \\
40 \\
46 \\
81\end{array}$ & $\begin{array}{l}15 \\
15 \\
23 \\
10\end{array}$ & $\begin{array}{l}14 \\
30 \\
23 \\
16\end{array}$ & $\begin{array}{r}71 \\
63 \\
48 \\
6\end{array}$ & $\begin{array}{r}7 \\
10 \\
17 \\
50\end{array}$ & $\begin{array}{r}0 \\
7 \\
17 \\
38\end{array}$ & $\begin{array}{r}21 \\
20 \\
17 \\
6\end{array}$ \\
\hline $\begin{array}{r}\text { Ferrara: } \\
14-17 \\
18-20 \\
21-24 \\
\geqslant 25\end{array}$ & $\begin{array}{l}21 \\
18 \\
15 \\
5\end{array}$ & $\begin{array}{r}62 \\
33 \\
7 \\
0\end{array}$ & $\begin{array}{r}29 \\
17 \\
47 \\
100\end{array}$ & $\begin{array}{r}10 \\
50 \\
47 \\
0\end{array}$ & $\begin{array}{r}25 \\
9 \\
10 \\
8\end{array}$ & $\begin{array}{r}80 \\
11 \\
10 \\
0\end{array}$ & $\begin{array}{r}8 \\
44 \\
50 \\
38\end{array}$ & $\begin{array}{l}\text { Not recorded } \\
\text { Not recorded } \\
\text { Not recorded } \\
\text { Not recorded }\end{array}$ & $\begin{array}{l}44 \\
44 \\
40 \\
63\end{array}$ \\
\hline
\end{tabular}


Table 2 Occupation of thalassaemic patients aged 15-24 years in comparison with that of general population of the same age. Values are expressed as percentages of each group

\begin{tabular}{llllll}
\hline & Athens & & & Ferrara & \\
\cline { 2 - 3 } & $\begin{array}{l}\text { General } \\
\text { population* }\end{array}$ & Patients & & $\begin{array}{l}\text { General } \\
\text { population }\end{array}$ & Patients \\
Employed & 24 & & & & \\
Studying & 57 & 55 & & 39 & 27 \\
Unemployed & 19 & 23 & & 24 & 42 \\
\hline
\end{tabular}

*Source: Focus Social Research Centre.

Table 3 Self image of patients in Ferrara. Values are expressed as percentages of each group

\begin{tabular}{lrr}
\hline & Self & Others \\
\hline Do you consider yourself/think & & \\
that others consider you: & 70 & 74 \\
A normal person & 24 & 23 \\
Sick but can handle own problems & 2 & 2 \\
Sick and cannot handle own problems & 6 & \\
\hline
\end{tabular}

Table 4 Self image of patients in Athens. Values are expressed as percentages for each variable

\begin{tabular}{llll}
\hline & Agree $^{*}$ & Neutral & Disagree* $^{*}$ \\
\hline Don't like to be centre of attention & 37 & 32 & 31 \\
I give up easily & 39 & 14 & 47 \\
It's best to let others decide for you & 19 & 18 & 63 \\
If find it difficult to make friends & 28 & 12 & 60 \\
I don't attach much importance to my appearance & 30 & 14 & 56 \\
\hline
\end{tabular}

*Completely or partly. the same age range), that only two of the Greek adult patients were married, that few patients in Ferrara had advanced to higher education, and that the percentage of Italian patients with jobs was substantially lower than that in the general population, indicate the kind of problems that may arise. Even so, more than a quarter of the Italian patients were employed. In Athens, the distribution of occupations already matched that of the general population at the time of the survey and subsequently even more of the sample have found jobs as a result of recent legislation favouring the chronically ill and other groups with special needs, within the frame work of governmental policy for social integration.

The effect of legislation is also evident in the high percentage of the Greek sample who were studying at university or had completed university education (34\% of those aged over 18 years, compared with $22 \%$ in the general population aged 18-34 years). Thalassaemic patients in Greece are able to benefit from exemption from university entrance examinations; this compensates for the interference of the disease and the demands of treatment with the thalassaemic child's education, although the desirability of such special provisions is not universally accepted within the patients' and parents' associations.

The self image of patients in both groups seemed to be quite good. There was some indication that unemployed patients might have a poorer self image. If this result can be confirmed in further investigations, it will emphasise the importance of achieving social integration to aid the patient's wellbeing. It is the policy of the World Health Organisation to support the integration of chronically ill people into the community; in the case of thalassaemia, the improved prognosis as a result of therapeutic advances means that current concepts of what is needed must be reevaluated. A combined medical and psychosocial approach demands not only the necessary managerial team but also a different attitude on the part of health authorities and even more of society. The data presented here suggest that such reorientation can have a considerable impact.

The results described in this paper show what has been achieved in two centres staffed by comprehensive therapeutic teams who encourage the independence of the patients and their psychosocial integration to the fullest possible degree. Furthermore, both centres offer continuity of support to the patient as the potentially traumatic referral to other units at adolescence is avoided. We strongly believe that this strategy is the key to the successful integration of thalassaemic patients, and we suggest that this kind of management is generally appropriate for chronically ill people.

1 Weatherall DJ, Clegg JB. The thalassaemia syndromes. Oxford: Blackwell Scientific, 1981.

2 Modell B, Berdoukas V. The clinical approach to thalassaemia. New York: Grune and Stratton, 1984.

3 Modell B. An overview of clinical aspects of thalasaemia management. In: Sirchia G, Zanella A, eds. Thalassaemia today: 2nd Mediterranean meeting on thalassaemia, 1985. Milan: Centro Transfusionale Ospedale Maggiore Policlinico di Milano, 1987:81-8.

4 Massaglia P, Carpigano M. Psychology of the thalassaemia patient and his family. In: Sirchia $G$, Zanella $A$, eds. patient and his family. Thalassaemia loday: 2nd Medicerranean meeting on thalassaemia, 1985. Milan: Centro Transfusion

5 Woo R, Giardina PJV, Hilgarther MW. Psychosocial needs assessment of patients with homozygous $\beta$-thalassaemia. assessment of patients with homozygo
Ann $N Y$ Acad $S c i 1984 ; 445: 316-22$

6 Cavalli A, De Lillo A. Giovani anni 80: secondo repporto IARD sulla condizione giovanile in Italia. Bologna: II Mulino, 1987. the less, had received no more than elementary education (compared with $8 \%$ of the general population in 